\title{
El saldo a favor del impuesto a la renta y la compensación - límites
}

Marisela Gallardo Quiroz ${ }^{(*)}$

Abogada por la Universidad San Martín de Porres. Especialización en Tributación Internacional por la Universidad Peruana de Ciencias Aplicadas - UPC y Leiden University. Maestría en Derecho Tributario en la Universidad San Martín de Porres.

(*) Este artículo fue realizado gracias a la ayuda de Araceli Ayala, alumna del décimo ciclo de la Facultad de Derecho de la Universidad Católica Sedes Sapientiae. 


\title{
RESUMEN:
}

La autora, a través de este ensayo, pretende exponer acerca del Crédito Tributario, explicando su relación con el Impuesto Valor Agregado y, sobre todo, con el concepto de saldo a favor del impuesto a la renta y su compensación. De este modo, se menciona el peso de la declaración del deudor y de la participación de la Administración Tributaria en este proceso.

Palabras clave: Crédito Tributario, Impuesto Valor Agregado, Impuesto a la Renta, saldo a favor, compensación, SUNAT, declaración del deudor, IGV

\begin{abstract}
:
The author, through this essay, intends to expose about the Tax Credit, explaining its relationship with the Value Added Tax and, above all, with the concept of the balance in favor of income tax and its compensation. Therefore, the weight of the declaration of the debtor and the participation of the Tax Administration in this process are mentioned.

Keywords: Tax Credit, Value Added Tax, Income Tax, balance in favor, compensation, SUNAT, declaration of the debtor, IGV
\end{abstract}

Primero, pasaremos a definir el concepto de Crédito Tributario. En ese sentido, tenemos por ejemplo en relación al Impuesto Valor Agregado - IVA que, para el Sistema Tributario Ecuatoriano", éste es un "(...) elemento destacado y esencial del IVA que denota su esencia para gravar el consumo, en la medida que admite descontar el impuesto pagado en las compras (...)". Además, aplicado a las retenciones se indica que "(...) El valor retenido constituye un crédito para quien fue objeto de la retención, para deducirse del IVA percibido en sus ventas por pagar al Estado (...)". Es decir, el crédito tributario será aquello que puede ser aplicado por el contribuyente contra un impuesto para reducir el importe a pagar. Sin embargo, si el crédito es mayor que el impuesto, el resultado que se obtendrá será un saldo a favor, el cual a su vez constituye un crédito tributario, ya que es un remanente del crédito inicialmente aplicado.

En ese sentido, la Ley de Régimen Tributario Interno del mismo país, establece que:

"Cuando por cualquier circunstancia evidente se presuma que el crédito tributario resultante no podrá ser compensado con el IVA causado dentro de los seis meses inmediatos siguientes, el sujeto pasivo podrá solicitar al Director Regional o Provincial del Servicio de Rentas Internas la devolución o la compensación del crédito tributario originado por retenciones que le hayan sido practicadas (...)".2.

Esto es, que al haber un crédito tributario que no puede ser aplicado contra el impuesto, se podrá solicitar la devolución o compensación.

Ahora bien, el crédito tributario es entendido del mismo modo en la legislación peruana, por ejemplo, a través del Impuesto a la Renta. Así, el inciso b) del artículo 88 de la Ley del Impuesto a la Renta - LIR señala que "Los contribuyentes obligados o no a presentar las declaraciones a que se refiere el artículo 79, deducirán de su impuesto, entre otros, los pagos efectuados a cuenta del impuesto liquidado en la declaración y los créditos contra dicho tributo". Asimismo, el artículo 52 del Reglamento de la LIR indica que "Los conceptos previstos en el Artículo 88 de la Ley constituyen crédito contra el Impuesto". Efectivamente, los pagos a cuenta vendrían a ser un crédito

1. Xavier Fernando Molina Herrera, "Crédito tributario: el problema de liquidez en las empresas" (tesis de maestría, Facultad Latinoamericana de Ciencias Sociales sede Ecuador, 2010), 91, https://repositorio.flacsoandes.edu.ec/ bitstream/10469/5431/2/

2. Ibíd. 
aplicable contra el impuesto a la renta determinado en la declaración jurada anual, resultando al final en un menor importe a pagar, o en un saldo a favor del contribuyente en caso de que el monto de los pagos a cuenta sea mayor al determinado en el impuesto. Siendo que, el saldo a favor también constituiría un crédito al ser un remanente del inicialmente aplicado, en este caso, los pagos a cuenta. Por lo tanto, éste podría ser objeto de una devolución o compensación.

Así lo establece el artículo 87 de la LIR cuando señala con respecto al saldo a favor generado que "(...) la SUNAT, previa comprobación, devolverá el exceso pagado", agregando que, "Ios contribuyentes que así lo prefieran podrán aplicar las sumas a su favor contra los pagos a cuenta mensuales que sean de su cargo, por los meses siguientes al de la presentación de la declaración jurada, de lo que dejarán constancia expresa en dicha declaración, sujeta a verificación por la SUNAT". Asimismo, el numeral 4 del artículo 55 del Reglamento del Impuesto a la Renta, indica que:

"El saldo a favor originado por rentas de tercera categoría generado en el ejercicio inmediato anterior deberá ser compensado sólo cuando se haya acreditado en la declaración jurada anual y no se solicite devolución por el mismo y únicamente contra los pagos a cuenta cuyo vencimiento opere a partir del mes siguiente a aquél en que se presente la declaración jurada donde se consigne dicho saldo".

Entonces, cabe preguntarnos si de acuerdo a estos artículos, el saldo a favor del impuesto a la renta únicamente podría compensarse con los pagos a cuenta y no con otros tributos.

Al respecto, el Tribunal Fiscal se ha pronunciado a través de la Resolución N 08679-3-2019 que constituye jurisprudencia de observancia obligatoria, estableciendo como criterio que:

"Si bien el deudor tributario no puede efectuar la compensación automática del saldo a favor del impuesto a la renta con deudas distintas a los pagos a cuenta de dicho impuesto, ello no implica una prohibición para que, a solicitud de parte, la Administración efectúe la referida compensación, conforme con lo previsto por el artículo 40 del Código Tributario".

En ese sentido, coincidimos con el Tribunal al señalar que los artículos 87 de la LIR y 55 del Reglamento, hacen referencia a una compensación automática, toda vez que ésta, a diferencia de las otras formas de compensación contempladas en el Código Tributario, no requiere que la Administración Tributaria -en el caso peruano la Superintendencia Nacional de Aduanas y de Administración Tributaria - SUNAT- reconozca el crédito determinado, bastando la sola declaración del deudor. Así lo hace notar el profesor Hernández Berenguel ${ }^{3}$, cuando indica que, si bien después de la entrada en vigencia del Decreto Legislativo 769 ya no se condiciona la compensación a que el crédito se encuentre liquidado y sea exigible; es decir, que sea reconocido por la Administración Tributaria, debe interpretarse que esta exigencia se mantiene, "(...) salvo los casos en que la compensación automática ha sido regulada, siendo suficiente, la simple declaración del deudory sin necesidad del reconocimiento del crédito(...)". Esto lo podemos observar al indicarse que, los contribuyentes "podrán aplicar las sumas a su favor contra los pagos a cuenta mensuales (...)" y sobre esto "dejarán constancia expresa en la declaración jurada".

Por lo tanto, si bien los artículos en mención señalan que la compensación automática únicamente se puede realizar contra los pagos a cuenta, esto no quiere decir, tal y como lo ha señalado el Tribunal Fiscal, que se excluya la posibilidad de realizar una compensación a solicitud de parte o inclusive una de oficio, considerando otras deudas tributarias.

Cabe precisar que, el artículo 40 del Código Tributario señala que: 
"La deuda tributaria podrá compensarse total o parcialmente con los créditos por tributos, sanciones, intereses y otros conceptos pagados en exceso o indebidamente, que correspondan a períodos no prescritos, que sean administrados por el mismo órgano administrador y cuya recaudación constituya ingreso de una misma entidad".

Asimismo, ésta puede realizarse en cualquiera de las siguientes formas: 1) compensación automática, en los casos establecidos por ley4; 2) compensación de oficio, donde la Administración será quien señale los supuestos en los que opera; 3) compensación a solicitud de parte, la que será efectuada por la Administración Tributaria previo cumplimiento de los requisitos, forma, oportunidad y condiciones que ésta señale.

Es así que mediante Resolución de Superintendencia N¹75-2007/SUNAT, la Administración Tributaria estableció los requisitos, forma, oportunidad y condiciones que deben cumplirse para que la compensación a solicitud de parte se realice. Así, el numeral 1 del artículo 5 de la mencionada norma señala como uno de los requisitos, la presentación del Formulario virtual $N^{\circ} 1648$ por cada Crédito Materia de Compensación, el cual en el presente caso vendría a ser el saldo a favor del Impuesto a la Renta. Se debe tener en cuenta que, para registrar el concepto de deuda a compensar, ésta debe estar consignada en una Declaración Jurada o en un valor - Resolución de determinación, multa u orden de pago entre otros-.

Entonces, el saldo a favor del Impuesto a la Renta puede compensarse a solicitud de parte contra otras deudas tributarias, siempre que, entre otros requisitos legales, sean administradas por la SUNAT y correspondan a tributos que cons- tituyan ingreso del tesoro público, como el Impuesto General a las Ventas - IGV o el Impuesto Temporal a los Activos Netos - ITAN.

Sobre este punto es necesario señalar que, cuando se hace referencia a ingresos del tesoro no en todos los casos se puede aplicar el saldo a favor; es decir, no se puede compensar contra cualquier tributo del tesoro público, pues esto dependerá también de las normas aplicables al impuesto contra el que se desea realizar la compensación.

Un ejemplo de ello es el IGV por utilización de servicios de no domiciliado, en donde la calidad de contribuyente la asume el sujeto domiciliado que utilizó el servicio y es quien deberá realizar el pago del IGV a la SUNAT. En ese sentido el artículo 21 del Texto Único Ordenado - TUO de la ley del IGV señala que “(...) el crédito fiscal podrá aplicarse únicamente cuando el Impuesto correspondiente hubiera sido pagado"; es decir, si quiero hacer uso del crédito fiscal primero debo pagar el referido impuesto a la SUNAT. A razón de ello se le exime al contribuyente de presentar declaración jurada de este impuesto 5 .

Ahora, la norma señala el pago como la forma de extinción de la obligación tributaria por lo que no se podría aplicar la compensación ya que ésta es otra forma de extinción diferente al pago. En ese sentido, nos preguntamos al no presentarse declaración jurada para este impuesto, no se puede realizar una compensación a solicitud de parte a través del formulario virtual $N^{\circ} 1648$ ya que es necesario que la deuda a compensar esté consignada en una declaración jurada o en un valor. Siendo así, no se podría compensar el saldo a favor del Impuesto a la Renta con el IGV por utilización de servicios de no domiciliado.

4. Por ejemplo, la aplicación del Saldo a Favor Materia del Beneficio — SFMB contra los pagos a cuenta del Impuesto a la Renta conforme a lo establecido en el artículo 34 del Texto Único Ordenado de la Ley del Impuesto General a las Ventas.

5. Artículo 5 de la Resolución de Superintendencia Nº87-99/SUNAT. 
No obstante, es importante tener en cuenta que lo que si se encuentra regulado es la compensación del Saldo a Favor Materia del Beneficio contra el IGV por utilización de servicios de no domiciliado, señalándose para ello, en la Resolución de Superintendencia N087-99/ SUNAT, que se deberá presentar una comunicación por escrito a la SUNAT; para solicitar la compensación. Hecho que no se encuentra regulado para otros créditos a pesar de que estamos ante un tributo que constituye ingreso del tesoro público.

De otro lado, es importante precisar en relación al tema expuesto que tenemos que, acuerdo lo establecido en el último párrafo del artículo 43 del Código Tributario, la acción para solicitar o efectuar la compensación prescribe a los cuatro años, por lo que éste es el tiempo que tienen los contribuyentes para realizar una compensación a solicitud de parte o automática, tomando en cuenta que existen causales de interrupción y suspensión de la prescripción. ${ }^{6}$ De esta manera, se pueden utilizar los créditos tributarios de acuerdo a la planificación fiscal que se tenga; siendo que, transcurrido dicho periodo de prescripción, los créditos ya no podrán deducirse del impuesto a pagar.

Finalmente cabe señalar que de acuerdo al artículo 162 del Código Tributario, cuando se trate de un procedimiento no contencioso, en este caso una solicitud de compensación de parte, la Administración tributaria tendrá un plazo no mayor a 45 días hábiles para evaluar y resolver sobre la procedencia de la solicitud de compensación.? Si ésta fuera declarada improcedente, y el contribuyente no estuviera de acuerdo con la decisión, tendrá expedito su derecho de interponer un recurso de apelación conforme a lo establecido en el artículo 163 del mismo código. $\mathrm{Si}$, por otro lado, no obtuviera pronunciamiento vencido el plazo indicado, se entenderá que ha sido denegada su solicitud - silencio administrativo negativo- por lo que tendrá que interponer una reclamación por denegatoria ficta.

6. Contempladas en el numeral 4 del artículo 45 y el numeral 3 del artículo 46 del Código tributario.

7. Procedimiento 59 regulado en el Texto Único de Procedimientos Administrativos de la SUNAT. 